Afr. J. Trad. CAM (2006) 3 (1): 115 - 128

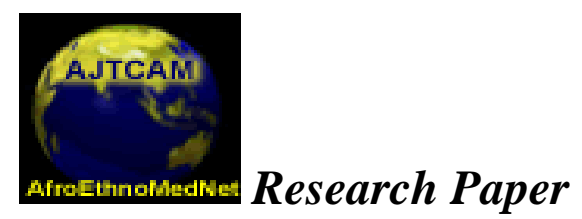

Afr. J. Traditional, Complementary and Alternative Medicines www.africanethnomedicines.n

\title{
ISSN 0189-6016@2006
}

EXPERIMENTAL DESIGN OPTIMIZATION FOR SCREENING RELEVANT FREE PHENOLIC ACIDS FROM VARIOUS PREPARATIONS USED IN BURKINA FASO FOLK MEDICINE

\author{
Martin Kiendrebeogo ${ }^{a, *}$, Luc Choisnard ${ }^{b}$, Charles E. Lamien ${ }^{a}$, Aline Meda ${ }^{a}$, Denis \\ Wouessidjewe $^{\mathrm{b}}$, Odile G. Nacoulma ${ }^{\mathrm{a}}$ \\ a Laboratoire de Biochimie et de Chimie Appliquées, UFR Sciences de la Vie et de la Terre, \\ Université de Ouagadougou, 03 BP 7021 Ouagadougou 03, Burkina Faso \\ Département de Pharmacochimie Moléculaire (DPM), UMR CNRS 5063, \\ Pharmacotechnie, Université Joseph Fourier, 38243 Meylan Cedex, France \\ E-mail: martin.k@univ-ouaga.bf, kmartin71@hotmail.com
}

\begin{abstract}
Experimental design methodology was used to optimize the HPLC separation of various relevant phenolic acids from an artificial mixture. The effect of four characteristic factors of the HPLC procedure on the Chromatographic Response Function was investigated by a Central Composite Face-Centred Design and Multi Linear Regression fitting. The eight phenolic acids were successfully separated. The optimal HPLC setting condition was applied to rapid screening of free phenolic acids from Striga hermonthica (Del.) Benth. (Scrophulariaceae), Guiera senegalensis J. F. Gmel (Combretaceae) and unifloral honey from Acacia sp. (Mimosaceae). None of reference phenolic acid was identified in S. hermonthica extract when some of them were detected in G. senegalensis and honey extracts. This work is considered as a first step for a largest phenolic acids screening from various preparations used in Burkina Faso folk medicine to justify some of their properties or potentialities.
\end{abstract}

Key words: Central Composite Face-Centred Design, Chromatographic Response Function, Phenolic acids

\section{Introduction}

Phenolic acids are plant secondary metabolites widely spread throughout the plant kingdom (Bruneton, 1993; Herrmann, 1989). Recent interest in phenolic acids stems from 
Afr. J. Trad. CAM (2006) 3 (1): 115 - 128

their potential as protective factors against cancer and heart diseases in part because of their potent antioxidative properties (Breinholt, 1999). They are also known to exhibit antibacterial effects (Weston et al., 1999) antimutagenic and anti-inflammatory activities in bacteria and mammalian (Loarca-Pina et al., 1998; Ihantola-Vormisto et al., 1997; Kaur et al. 1997). Besides, some phenolic acids were reported to be potent and selective inhibitors of human immunodeficiency virus type 1 (HIV-1) integrase (Middleton et al., 2000). Therapeutic uses of medicinal plants in Burkina Faso folk medicine could partly be assigned to their free phenolic acids (Nacoulma, 1996). A screening program on free phenolic acids in medicinal plants and foods from Burkina Faso is then undergoing in our laboratory to justify some their biological properties and potentialities.

The potential healthful of phenolic acids have prompted the interest in developing analytical methodologies for their detection and measurement from plant sources. A number of analytical techniques have been presented for the analysis of phenolic acids, including thin-layer chromatography (Schmidtlein and Herrmann, 1975), gas-liquid chromatography (Schulz and Herrmann, 1980), gas chromatography-mass spectrometry (Wu et al., 1999), or capillary electrophoretic methods (Fernandez et al, 1996). However, high-performance liquid chromatography is presently the most widely used method (Amakura et al., 2000; Escarpa and Gonzales, 2000; Hahn et al., 1983). Despite the numerous HPLC methods for phenolic acids determination described in the literature, an optimized method, convenient for all phenolic acids from complex mixture like plant extracts is not available to our knowledge. Hence, this study aimed to develop an optimized HPLC method for the separation of caffeic, ferulic, vanillic, ellagic, gallic, benzoic, cinnamic and hydrocinnamic acids. Their choice was focused either on their relatively close structure and their well-known antimutagenic, antibacterial, antioxidant and anti-inflammatory activities (Rukkumani et al., 2004; Friedman et al., 2003; Op de Beck et al., 2003; Privadiarsin et al., 2002; Fernandez et al., 1998; Kaur et al., 1997; Fernandez et al., 1996; Garcia and Marhuenda, 1985; Wood et al., 1982).

The selection of optimal HPLC operating conditions is rather difficult and complex for multi-component mixtures due to the high degree of process variable interaction. Several process variables must be investigated. HPLC methods development was traditionally accomplished through a trial-and-error process. This procedure is overly expensive due to both the time involved and the potential product wasted in the many experiments that must be performed to find acceptable, though not necessarily optimal, operating conditions. Experimental design methodologies, more practical and efficient, have been reported as a suitable tool to optimize HPLC separations (Karnka et al., 2002; Onjia et al., 2002; Klein and Rivera, 2000). It involves a statistical design of experiments, which uniformly samples the experimental domain to generate an experimental test matrix. Response or criteria functions are employed to quantify results numerically and rank chromatograms in order of their desirability. These criteria functions are mapped to response surface models, which are then optimized within the constraints of the experimental domain with respect to the process variables.

In this paper, we propose an experimental design with HPLC for a suitable separation of caffeic, ferulic, vanillic, ellagic, gallic, benzoic, cinnamic and hydrocinnamic acids 


\section{Afr. J. Trad. CAM (2006) 3 (1): 115 - 128}

mixture. The optimization process was carried out on an artificial mixture and the optimal HPLC setting applied to biological samples.

\section{Material and Methods}

Whole plant Striga hermonthica (DEL.) Benth (Scrophulariaceae) and galls from Guiera senegalensis J. F. Gmel (Combretaceae) were collected at Gampela $(25 \mathrm{~km}$, east of Ouagadougou, Burkina Faso). After being identified by Prof. Millogo, voucher specimens were deposited at the herbarium of the University of Ouagadougou as Lamien 01 (galls from Guiera senegalensis) and Kiendrebeogo 01 (Striga hermonthica). Honey sample $\left(n^{\circ} 3\right)$ was collected from the east of Burkina Faso. Pollen morphologies were compared with reference slide from the Laboratory of Biology and Ecology, University of Ouagadougou. Sample was identified as Acacia sp. unifloral honey (Meda et al., 2005).

\section{Test samples preparation}

Plant extracts were obtained by refluxing $10 \mathrm{~g}$ of powdered material for $30 \mathrm{~min}$ with $100 \mathrm{ml}$ of aqueous acetone $80 \%$. Acetone was removed under reduced pressure and the aqueous residue freeze-dried. A $10 \mathrm{mg} / \mathrm{ml}$ solution was made from a (1:1) methanol/water solution for HPLC analysis. Honey sample $(25 \mathrm{~g})$ was mixed with $125 \mathrm{ml}$ acidic water $\mathrm{pH} 2$ and filtered through an amberlite XAD2 column $(25 \times 2 \mathrm{~cm})$. The column was eluted with $100 \mathrm{ml}$ of acidic water $\mathrm{pH} \mathrm{2,300} \mathrm{ml} \mathrm{of} \mathrm{water} \mathrm{and} \mathrm{then} 300 \mathrm{ml}$ of methanol. Methanolic fraction was concentrated under reduced pressure and partitioned between water and diethyl ether. The organic phase was dissolved in $1 \mathrm{ml}$ methanol for HPLC analysis. HPLC Chromasolv ${ }^{\circledR}$ methanol and G Chromasolv ${ }^{\circledR}$ water (Flucka chemie $\mathrm{GmbH}$, Switzerland) were used to prepare samples solutions for HPLC analysis.

\section{Artificial Phenolic acids mix}

Phenolic acids (caffeic, ferulic, cinnamic, hydroxycinnamic, gallic, vanillic, benzoic, ellagic acid) were purchased from Sigma. Their structures and CAS numbers are given in Fig. 1. Standard mixture solution made in methanol $(100 \mu \mathrm{g} / \mathrm{ml}$ of each of all phenolic acids) was used for the optimization procedure.

\section{HPLC system and chromatographic separation efficiency estimation}

The liquid chromatographic system consisted of a Varian 9012 pump module, a Varian 9100 automatic sampler and a Varian 9065 UV detector. Star Chromatography Workstation software version 5.51 was used to acquire and analyse chromatographic data. All the experiments were performed on Kromasil $\mathrm{C}_{18}$ column $(250 \mathrm{~mm} \times 4.6 \mathrm{~mm}$ internal diameter, $10 \mu \mathrm{m}$ particle size, $100 \AA$ pore size). Ultraviolet detection was achieved at 210 $\mathrm{nm}$ and $273 \mathrm{~nm}$. Samples $(20 \mu \mathrm{l})$ were injected in triplicate. Gradient elution regimes were employed using HPLC Chromasolv ${ }^{\circledR}$ acetonitrile and $0.1 \%(\mathrm{v} / \mathrm{v})$ orthophosphoric acid in 
Afr. J. Trad. CAM (2006) 3 (1): 115 - 128

G Chromasolv ${ }^{\circledR}$ water (Fluka chemie GmbH, Switzerland). Orthophosphoric acid (85 \%) was HPLC grade (Fischer scientific). The quality of chromatographic separation has been evaluated by the Chromatographic Response Function (CRF) (Karnka et al., 2002; Klein and Rivera, 2000). The CRF (Eq. 1) is a global quality criterion that allows specifying time and resolution parameters.

Eq. 1. $C R F=\sum R_{i}+L^{a}-b\left|T_{M}-T_{L}\right|-C\left(T_{0}-T_{1}\right)$

Where $R_{i}$ is the resolution between adjacent pairs of peaks, $L$ the total number of peaks, $T_{M}$ the maximal acceptable duration of analysis, $T_{L}$ the retention time of the last eluted peak, $\mathrm{T}_{0}$ the specified minimum retention time and $\mathrm{T}_{1}$ the retention time of the first eluted peak. $\mathrm{a}, \mathrm{b}$ and $\mathrm{c}$ are the arbitrary weighting factors. To maximize L parameter, the weighting factors were fixed as following: $a=2, b=1$ and $c=1$. All $R_{i}$ values exceeding 2.0 were systematically discarded from CRF calculation to avoid overestimated CRF.

\section{Experimental design}

Experimental design was processed and analyzed using Modde 5.0 software. Central Composite Face-Centred Design (CCFD) was used because it requires only three levels for each factor and lead to a quadratic model (Eq. 2) which is efficient to describe a potentially complex function:

Eq. 2. $\eta=\beta_{0}+\sum_{i=1}^{k} \beta_{i} x_{i}+\sum_{\substack{i, j=1 \\ i=j}}^{k} \beta_{i j} x_{i} x_{j}+\sum_{i=1}^{k} \beta_{i i} x_{i}^{2}$

Where $\eta$ is computed response of CRF, $\beta_{0}$ the constant, $\beta_{\mathrm{i}}$ the linear coefficients, $\beta_{\mathrm{ij}}$ the cross product coefficients, $\beta_{\mathrm{ii}}$ the quadratic coefficients, $\mathrm{k}$ the number of independent factors. Normality of the experimental data was examined using the Box-Cox transformation procedure (Box and Cox, 1964). Model coefficients were estimated with the well known Multi Linear Regression (MLR), which allows fitting of the observed response with the analytical model (Box et al., 1978). Initial model including all the coefficients was refined using stepwise technique (Yin and Carter, 1996). This procedure involves removing step by step each eligible coefficient in regard to subsequent statistic quality of the model. The model efficiency was estimated by the coefficient of correlation $\mathrm{R}^{2}$, the coefficient of determination $\mathrm{R}_{\text {Adj }}^{2}$, the coefficient of prediction $\mathrm{Q}^{2}$ (Eq. 3) and the analysis of variance (ANOVA) based on the Fischer F-test.

Eq.3 $Q^{2}=\frac{\left[\sum_{1}^{n}\left(y_{i}-\bar{Y}\right)^{2}-\sum_{1}^{n}\left(\eta_{i}{ }^{\prime}-y_{i}\right)^{2}\right]}{\sum_{1}^{n}\left(y_{i}-\bar{Y}\right)^{2}}$ 


\section{Afr. J. Trad. CAM (2006) 3 (1): 115 - 128}

In this equation $\eta_{i}$ ' represent a prediction of the $i^{\text {th }}$ observed response made from a model regressed on all of the available data except the $i^{\text {th }}$ observation (Eriksson et al., 2000). Pvalues criteria estimated by Student t-test was employed to control the coefficient to be removed. In this iterative approach, coefficient with the minus P-value was removed from the sub-model of the step. Stepping was stopped when statistic criteria corresponding to the best sub-model were obtained. Optimisation of the experimental conditions was extrapolated using Nelder Mead simplex method module, as implemented in Modde 5.0 software (Nelder and Mead, 1965). Then, predicted response efficiency (Eq. 4) was evaluated by "distance to target" coefficient (D) applied in only one response case (Eriksson et al., 2000):

Eq. 3. $D=\log \left(\frac{\eta-T}{T-L}\right)^{2}$

Where $\eta$ is the computed response of CRF, $\mathrm{T}$ the desired response target and $\mathrm{L}$ the worst acceptable response value.

\section{Results and Discussion}

The CRF optimization study was carried out in two steps. First, the eight commercial phenolic compounds of interest were mixed together to obtain a complex test medium as a mimic of plant extract. The above artificial mix of the commercial phenolic acids was used to optimize the HPLC identification by surface method procedure. In a second step, the optimal HPLC procedure was applied to the screening of natural extract from Striga hermonthica, galls of Guiera senegalensis and honey sample.

The HPLC procedure was carried out in 3 steps:

(i) An initial isocratic elution during 15 min for column equilibration

(ii) A gradient elution during $\mathrm{X}_{3} \min$ (to be determined through the optimization procedure) for phenolic acids separation

(iii) A second gradient elution for $10 \mathrm{~min}$ followed by a $5 \mathrm{~min}$ isocratic elution to extract potentially by-products residuals from the HPLC column.

Elution solvent was composed of acetonitrile and orthophosphoric acid $0.1 \%$. Optimization of the chromatographic separation was investigated on four factors implicated in the $2^{\text {nd }}$ step (step ii): initial acetonitrile percentage $\left(\mathrm{X}_{1}\right)$, acetonitrile percentage at the end of the first gradient elution $\left(\mathrm{X}_{2}\right)$, duration of the first gradient elution $\left(\mathrm{X}_{3}\right)$ and pump flow rate during the first isocratic phase and the first gradient elution $\left(\mathrm{X}_{4}\right)$. Acetonitrile percentage as well as solvent flow rate at the end of the second gradient and during the last isocratic elution was settled at $75 \%$ and $1 \mathrm{ml} / \mathrm{min}$. The different factors levels values producing the experimental domain were chosen after brainstorming and some preliminary studies. Then $X_{1}$ interval values were chosen between 1 and $5 \%$ acetonitrile and $X_{2}$ values between 40 and $70 \%$ acetonitrile. $X_{3}$ interval was limited by 40 
Afr. J. Trad. CAM (2006) 3 (1): 115 - 128

and $50 \mathrm{~min}$ and $\mathrm{X}_{4}$ by 1 and $2 \mathrm{ml} / \mathrm{min}$. Artefacts caused by the different magnitudes and units of the factors were avoided using variables explained in a centred coded levels. For each factor, $(+1)$ constitute the high level value, $(-1)$ the low level value and $(0)$ the centred value.

Due to the potential complex interactions suspected between the factors, the experimental design was chosen to support a quadratic model. CCFCD was then investigated in 23

experimental runs including 3 central points. Run sequence of experimental units was completely randomized to minimize the effect of noise and the chromatographic separation quality was evaluated using CRF (Table 1). No deviating experiment (outlier) was detected using Normal probability plot.

\section{Chromatographic method optimization}

The Box-Cox transformation of experimental raw data gives $\lambda_{\text {lower }}=0.5539, \lambda_{\max }=$ $1.0297, \lambda_{\text {upper }}=1.5792$ at $95 \%$ confidence level. No data transformation was then necessary to improve the model (Draper and Smith, 1981; Box and Cox, 1964), assessing the normal distribution of experimental data. The model coefficients were obtained by fitting the worksheet data by MLR. Fig. 2 shows all the regression coefficients and their uncertainty given by $90 \%$ confidence interval. The best sub-model (Eq. 5) adopted by the stepwise technique for the CRF response was obtained as described in material and method section:

Eq. 4.

$$
\eta=49.313-11.1548 X_{1}-8.46117 X_{2}+3.56258 X_{3}+2.06971 X_{4}+3.03885 X_{1} X_{4}
$$

$$
+3.3337 X_{2} X_{3}-8.34727 X_{2} X_{4}-13.3077 X_{1}^{2}+6.59799 X_{2}^{2}-8.05465 X_{3}^{2}+7.0351 X_{4}^{2}
$$

The coefficient of correlation $\mathrm{R}^{2}=0.959$ and the coefficient of determination $\mathrm{R}^{2}{ }_{\text {Adjusted }}=$ 0.918 showed that quadratic model is well fitted by MLR. The CRF response is very well predicted as indicated by the coefficient of prediction $\mathrm{Q}^{2}=0.773$. Generally speaking, $\mathrm{Q}^{2}>$ 0.5 is considered to be good, $\mathrm{Q}^{2}>0.7$ very good, and $\mathrm{Q}^{2}>0.9$ excellent (Eriksson et al., 2000). Besides, $\mathrm{R}^{2}$ and $\mathrm{Q}^{2}$ difference was favourably inferior to 0.2 . The ANOVA analyse shows that probability for the model regression is significant at $95 \%$ (P-value $=0.000<<$ 0.05 ) but the probability for lack of fit is significant at $95 \%$ (P-value $=0.001<0.05$ ). However, the model validity was not dramatically depreciated by this slight lack of fit because the predictive power evaluated by the coefficient of prediction $\mathrm{Q}^{2}$ was greater than 0.5 (Eriksson et al., 2000). In the statistically point of view, the quadratic model appears good within the range of variables employed.

The positive sign of the linear coefficients $\left(\beta_{\mathrm{i}}\right)$ refers to an increasing effect on the

CRF response, whereas the negative sign indicate a decreasing effect on this response. Direct determination of optimal factor setting was very difficult in regard to the number and the antagonist influence of interaction and quadratic terms also implicated in the model. 
Afr. J. Trad. CAM (2006) 3 (1): 115 - 128

Table 1:Central Composite Face-Centred Design matrix and corresponding CRF response

\begin{tabular}{|c|c|c|c|c|c|c|}
\hline \multirow{2}{*}{$\begin{array}{l}\text { Experimental } \\
\text { unit }\end{array}$} & \multirow{2}{*}{$\begin{array}{l}\text { Run } \\
\text { Order }\end{array}$} & \multicolumn{4}{|c|}{ Experimental factors } & \multirow{2}{*}{$\mathrm{CRF}$} \\
\hline & & $\mathrm{X}_{1}$ & $\mathrm{X}_{2}$ & $\mathrm{X}_{3}$ & $\mathrm{X}_{4}$ & \\
\hline 1 & 1 & -1 & -1 & -1 & -1 & 53.7367 \\
\hline 2 & 14 & +1 & -1 & -1 & -1 & 27.2283 \\
\hline 3 & 22 & -1 & +1 & -1 & -1 & 51.3441 \\
\hline 4 & 8 & +1 & -1 & +1 & -1 & 21.6544 \\
\hline 5 & 18 & -1 & +1 & +1 & -1 & 54.0935 \\
\hline 6 & 9 & +1 & +1 & +1 & -1 & 36.1383 \\
\hline 7 & 15 & -1 & -1 & -1 & +1 & 66.9711 \\
\hline 8 & 2 & -1 & +1 & -1 & +1 & 27.8605 \\
\hline 9 & 6 & +1 & +1 & -1 & +1 & 12.3068 \\
\hline 10 & 16 & -1 & -1 & +1 & +1 & 68.5150 \\
\hline 11 & 20 & +1 & -1 & +1 & +1 & 52.1348 \\
\hline 12 & 3 & +1 & +1 & +1 & +1 & 27.3733 \\
\hline 13 & 10 & -1 & 0 & 0 & 0 & 51.2591 \\
\hline 14 & 17 & +1 & 0 & 0 & 0 & 21.638 \\
\hline 15 & 19 & 0 & -1 & 0 & 0 & 68.9428 \\
\hline 16 & 21 & 0 & +1 & 0 & 0 & 43.7657 \\
\hline 17 & 7 & 0 & 0 & -1 & 0 & 32.6095 \\
\hline 18 & 4 & 0 & 0 & +1 & 0 & 50.7937 \\
\hline 19 & 5 & 0 & 0 & 0 & -1 & 54.4539 \\
\hline 20 & 11 & 0 & 0 & 0 & +1 & 59.1288 \\
\hline 21 & 12 & 0 & 0 & 0 & 0 & 48.6639 \\
\hline 22 & 13 & 0 & 0 & 0 & 0 & 48.5918 \\
\hline 23 & 23 & 0 & 0 & 0 & 0 & 48.8198 \\
\hline
\end{tabular}

$(+1)$ high level value, (-1) low level value and (0) the centred value of each factor $\left(\mathrm{X}_{1}\right)$ initial and $\left(\mathrm{X}_{2}\right)$ final acetonitrile, $\left(\mathrm{X}_{3}\right)$ duration of the first gradient, $\left(\mathrm{X}_{4}\right)$ solvent flow rate of the first isocratic and first gradient elutions. 
Afr. J. Trad. CAM (2006) 3 (1): 115 - 128

Table 2: Phenolic acids suspected on the base of retention time

\begin{tabular}{lcccc}
\hline Phenolic acid $(\lambda \mathrm{nm})$ & RT $(\min ) \pm \mathrm{SD}$ & $\mathrm{S} . \mathrm{h}$ & G. s & Honey \\
\hline Benzoic acid; $273 \mathrm{~nm}$ & $4.59 \pm 0.06$ & - & - & - \\
Gallic acid; 210 and $273 \mathrm{~nm}$ & $5.96 \pm 0.08$ & - & $\mathrm{X}$ & - \\
Caffeic acid; 210 and $273 \mathrm{~nm}$ & $15.19 \pm 0.12$ & - & - & $\mathrm{X}$ \\
Vanillic acid; 210 and $273 \mathrm{~nm}$ & $15.89 \pm 0.15$ & - & $\mathrm{X}$ & $\mathrm{X}$ \\
Ferulic acid; 210 and $273 \mathrm{~nm}$ & $21.67 \pm 0.13$ & - & - & $\mathrm{X}$ \\
Ellagic acid; 210 and $\mathbf{2 7 3} \mathrm{nm}$ & $22.83 \pm 0.16$ & - & - & $\mathrm{X}$ \\
Hydrocinnamic acid; $210 \mathrm{~nm}$ & $32.12 \pm 0.07$ & - & - & $\mathrm{X}$ \\
Cinnamic acid; 210 and $\mathbf{2 7 3} \mathrm{nm}$ & $33.46 \pm 0.07$ & - & $\mathrm{X}$ & $\mathrm{X}$ \\
\hline
\end{tabular}

Mean value \pm Standard deviation of 3 injections

Wavelengths in bold character are preferably used

RT: retention time

$\mathrm{X}$ : Detected compounds

-: Non detected compounds

S.h: Striga hermonthica

G. s: Guiera senegalensis

For example, final acetonitrile proportion have a decreasing effect $\left(\beta_{2}=-8.4611\right)$ on CRF response but an increasing effect is observed in interactions with phase duration $\left(\beta_{23}=\right.$ $+3.3337)$, in interactions with pump flow rate $\left(\beta_{24}=+8.34727\right)$ and within quadratic effect $\left(\beta_{22}=+6.59799\right)$. Analysis was aided by surface response plot drawn from the model when varying two factors while the other factors were kept constant at the medium level $\left(\mathrm{x}_{\mathrm{i}}=0\right)$. For sake of simplicity, only the response 3D surface plot and corresponding 2D contour plot for $\mathrm{X}_{2}$ and the other significant factors set one by one were reported in Fig. 3. As illustrated, the CRF was maximized for the following setting parameters: the final concentration of acetonitrile (X2) was minimized, the initial concentration of acetonitrile $\left(\mathrm{X}_{1}\right)$ to about $2 \%$, the gradient duration $\left(\mathrm{X}_{3}\right)$ to about $45 \mathrm{~min}$ and the pump flow rate $\left(\mathrm{X}_{4}\right)$ to about $2 \mathrm{ml} / \mathrm{min}$.

Further, to determine more precisely the optimal factors range, a Nelder mead simplex method was investigated. This method has an advantage over the response surface plot and 2D contour plot because the response is optimized using all the factors in the same time. Then, an interesting value for CRF was arbitrary focused to 76 . The experimental conditions predicted by the model were: Initial acetonitrile $\left(X_{1}\right)=2 \%$; Final acetonitrile at the end of gradient $\mathrm{I}\left(\mathrm{X}_{2}\right)=43 \%$; Gradient I duration $\left(\mathrm{X}_{3}\right)=45 \mathrm{~min}$ and Flow rate $\left(\mathrm{X}_{4}\right)=2$ $\mathrm{ml} / \mathrm{min}$. 
Afr. J. Trad. CAM (2006) 3 (1): 115 - 128<smiles>O=C(O)c1ccccc1</smiles>

Benzoic ació [65-85-0]<smiles>O=C(O)C=Cc1ccccc1</smiles>

Cinnamic acid [140-10-3]<smiles>O=C(O)c1cc(O)c(O)c(O)c1</smiles>

Gallic aciod $[149-91-7]$

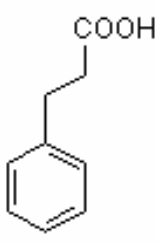

Hydrocinnamic acid [501-52-0]<smiles>COc1cc(C(=O)O)ccc1O</smiles>

Vanillic acid [121-34-6]<smiles>O=C(O)/C=C/c1ccc(O)c(O)c1</smiles>

Caffeic acid [331-39-5]<smiles>O=c1oc2c(O)c(O)cc3c(=O)oc4c(O)c(O)cc1c4c23</smiles>

Ellagic ació

[476-6G-4]<smiles>COc1cc(/C=C/C(=O)O)ccc1O</smiles>

Ferulic acid [11:35-24-6]

Figure 1: $\quad$ Structure and CAS number of Phenolic acids of study

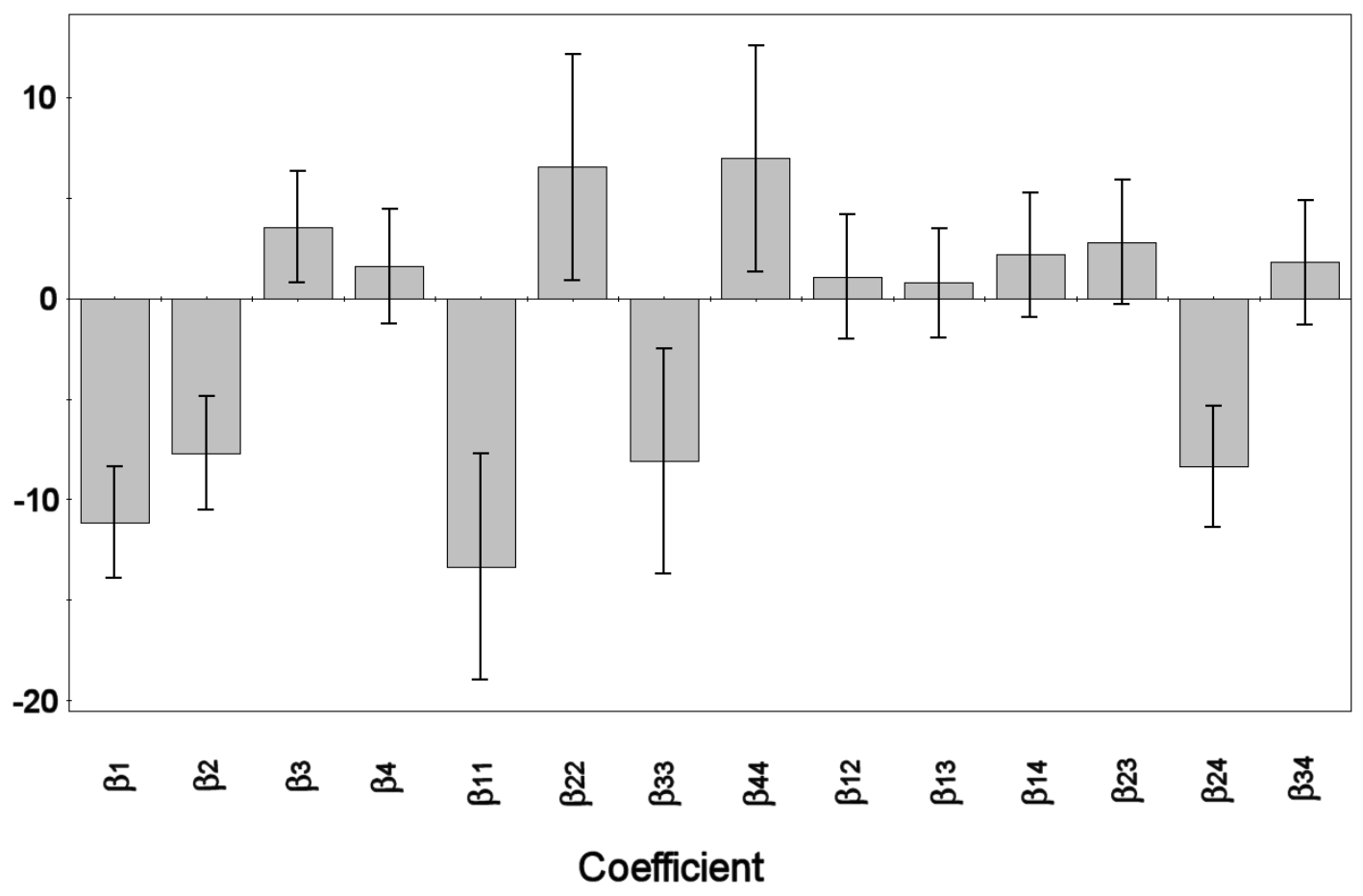

Figure 2: Regression coefficient plot obtained by MLR process 


\section{Afr. J. Trad. CAM (2006) 3 (1): 115 - 128}

Thus, factors settings were very close to the previous tendencies obtained by plot analysis. Experimental investigation was carried out with this experimental setting to check the adequacy of the model. Calculated CRF of 68.6 was in accordance with the predicted CRF value within confidence interval of $99 \%$. Consequently, the quadratic model was statistically and experimentally found to be good.

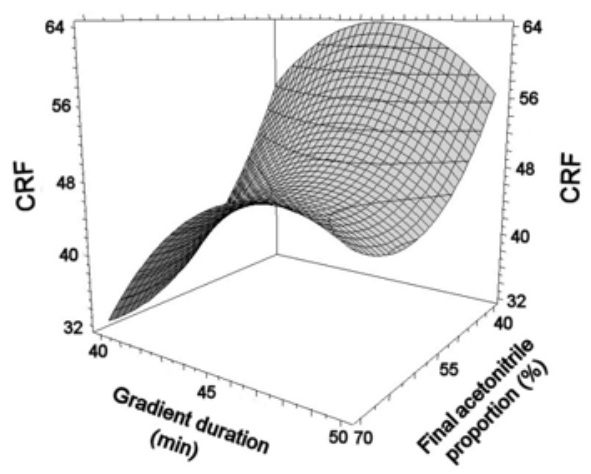

A

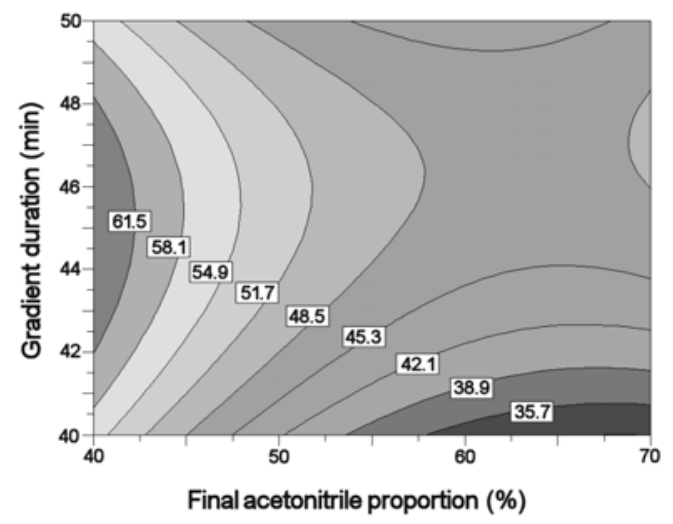

B
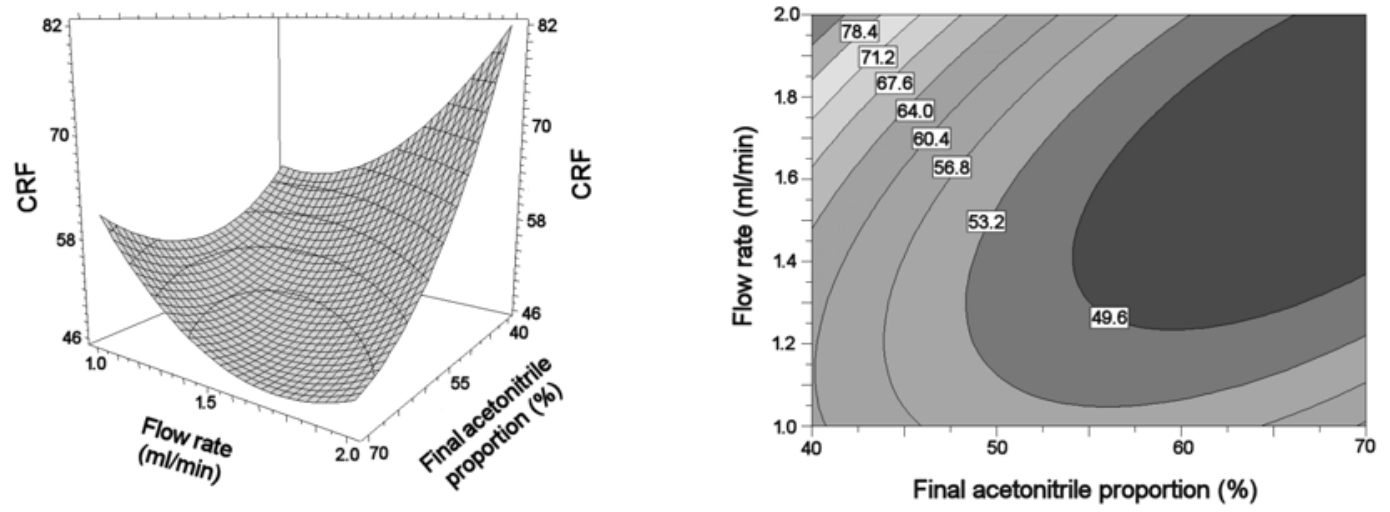

Figure 3: $\quad 3 \mathrm{D}$ response surface plot and corresponding 2D contour plot showing the variation of CRF values versus final acetonitrile proportion and gradient duration (A) or pump flow rate $(B)$.

The chromatographic profiles at 210 and $273 \mathrm{~nm}$ of the artificial phenolic acids mix obtained with the optimized HPLC method are illustrated by Fig 4. In our operating conditions, hydrocinnamic acid was only detected at $210 \mathrm{~nm}$ when benzoic acid was 
detected at $273 \mathrm{~nm}$. The other phenolic acids were detected at both 210 and $273 \mathrm{~nm}$. However, $210 \mathrm{~nm}$ is more suitable for gallic, caffeic, vanillic, ferulic and hydrocinnamic acids when ellagic and cinnamic acids were better detected at $273 \mathrm{~nm}$. The retention time and suitable wavelength corresponding to the different relevant free phenolic acids in the optimized HPLC procedure were summarized in Table 2. The optimized chromatographic method was successfully applied to the screening of free phenolic acids from Striga hermonthica, Guiera senegalensis and Acacia sp. honey. Results are summarized in Table 2. In comparison with the standard mix reference, relevant free phenolic acids may be encountered in galls of G. senegalenesis and the unifloral honey of Acacia sp., S. hermonthica didn't contain any. Gallic, vanillic and cinnamic acids were identified in $G$. senegalenesis when caffeic, vanillic, ferulic, ellagic hydrocinnamic and cinnamic acids were detected in the honey sample. In previously published work, gallic acid was identified in G. senegalenesis (Bouchet et al., 2000) when caffeic, vanillic, ellagic, hydrocinnamic and cinnamic acid were identified (Gheldorf et al., 2002; Thomas-Barberan et al., 2001; Amiot et al., 1989) from the unifloral honey of Acacia sp.
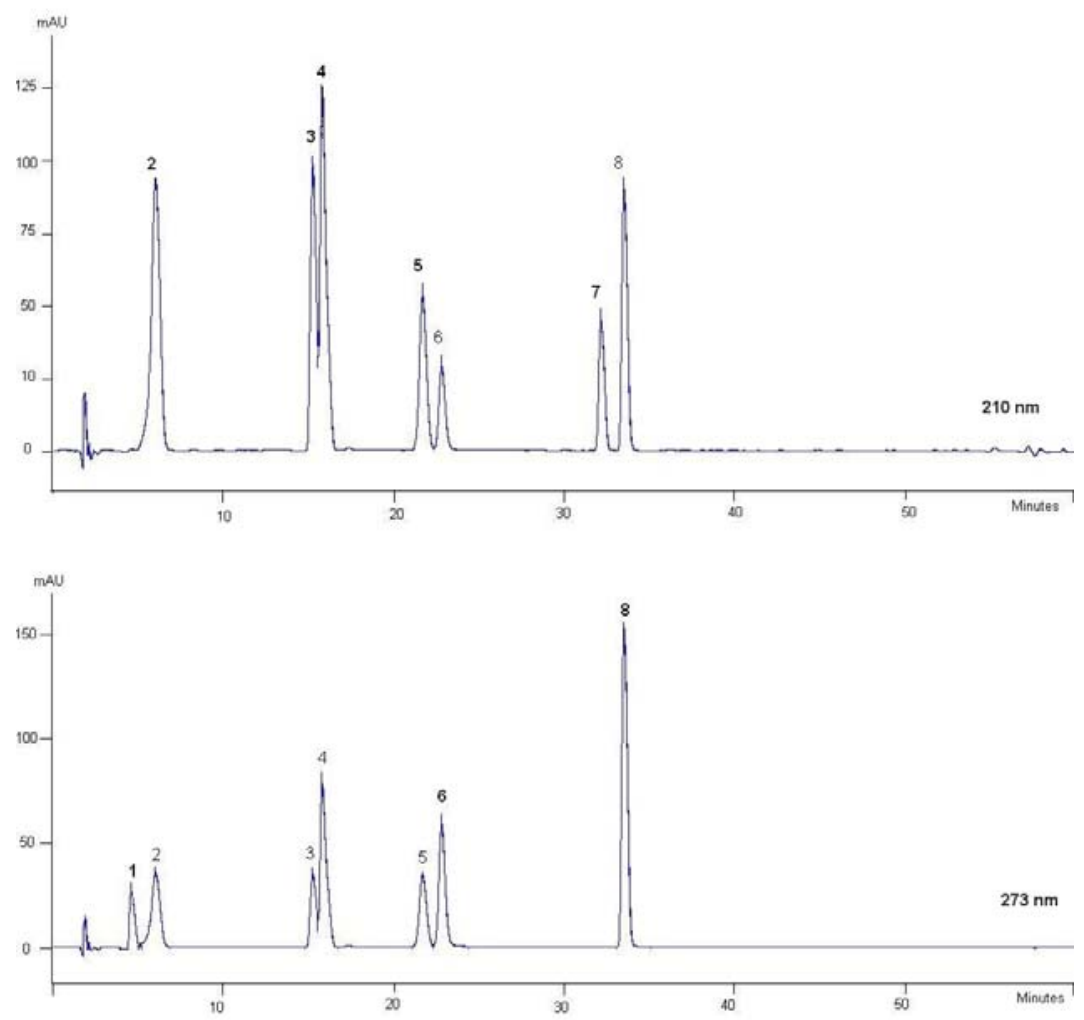

Figure 4: Optimized chromatographic separation of the artificial phenolic acids mix:

1 Benzoic acid, 2 Gallic acid, 3 Caffeic acid, 4 Vanillic acid, 5 Ferulic acid,6 Ellagic acid, 7 Hydrocinnamic acid, 8 Cinnamic acid at 210 and $273 \mathrm{~nm}$ 
Afr. J. Trad. CAM (2006) 3 (1): 115 - 128

\section{Conclusion}

In conclusion, this experimental design methodology allows us to set HPLC conditions for optimized separation of 8 relevant free phenolic acids. These conditions were successfully applied to the screening of S. hermonthica, G. senegalensis and honey extracts. This study is a preliminary to a largest screening of phenolic acids from Burkina Faso medicinal plants in order to correlate them with their antioxidant properties and biological benefits.

\section{Acknowledgments}

The authors are grateful to the International Atomic Energy Agency (IAEA) for providing the financial support BKF/03030P through TCP BKF/5/002 "Mise au point d'un médicament vétérinaire contre la variole aviaire" which allowed this study.

\section{References}

1. Amakura, Y., Okada, M., Tsuji, S. and Tonogai, Y. (2000). Determination of phenolic acids in fruit juices by isocratic column liquid chromatography. J. Chromatography A 891: 183-188.

2. Amiot, M. J., Aubert S., Gonnet M. and Tacchini M. (1989). Les composés phénoliques des miels: étude préliminaire sur l'identification et la quantification par familles. Apidologie 20: 115-125.

3. Bouchet N., Levesque J. and Pousset J. L. (2000). HPLC isolation, identification and quantification of tanins from Guiera senegalensis. Phytochemical analysis 11: 52-56.

5. Box G. E. P., and Cox, D. R. (1964). An Analysis of Transformations. Journal Royal Statistical Society B 26: 211-252.

6. Box, G. E. P., Hunter W. G. and Hunter J. S. (1978). Statistics for experiment: an introduction to design, data analysis, and model building. John Wiley \& Sons: New York, USA.

7. Breinholt, V. (1999). Desirable versus harmful levels of intake of flavonoids and phenolic Acids: In Natural Antioxidants and Anticarcinogens in Nutrition, Health and Disease.(Kumpulainen J., Salonen J.); The Royal Society of Chemistry: Cambridge, UK.

8. Bruneton, J. (1993). Pharmacognosie: Phytochimie-Plantes médicinales (2nd edition). Lavoisier TEC \& DOC: Paris, France.

9. Draper, N. R. and Smith, H. (1981). Applied Regression Analysis (2nd edition). John Wiley \& Sons: New York, USA.

10. Eriksson, L., Johansson E., Kettaneh-Wold N., Wikström C. and Wold S. (2000). Design of experiments, principles and applications. Umetrics Academy: Stockholm, Sweeden.

11. Escarpa A., Gonzalez M. C. (2000). Evaluation of high-performance liquid chromatography for determination of phenolic compounds in pear horticultural cultivars. Chromatographia 51: 37-43. 


\section{Afr. J. Trad. CAM (2006) 3 (1): 115 - 128}

12. Fernandez, M. A., Garcia, M. D. and Saenz, M. T. (1998). Anti-inflammatory activity in rats and mice of phenolic acids isolated from Scrophularia fructescens. J. Pharmacy Pharmacology 50(10):1183-1186.

13. Fernandez, J. B., Griffiths, D. W., Bain, H. and Fernandes, F. N. (1996). The development and evaluation of capillary electrophoretic methods for the determination of the major phenolic constituents of potato (Solanum tuberosum) tubers. Phytochemical Analysis 7:253-258.

14. Friedman, M., Henika, P. R. and Mandrell, R. E. (2003). Antibacterial activities of phenolic benzaldehydes and benzoic acids against Campylobacter jejun, Escherichia coli, Listeria monocytogenes and Salmonella enterica. J.food Protection 66(10): 18111821.

15. Garcia, M. D. and Marhuenda, E. (1985). Isolement et activité antimicrobienne de l'acide vanillique et de l'acide p-hydroxybenzoique constituant d'Onis natris. Fitoterapia 56(6): 349-350.

16. Gheldof, N., Wang, X. H. and Engeseth N. J. (2002). Identification and quantification of antioxidant components of honeys from various floral sources. J. Agriculture Food Chemistry 50: 5870-5877.

17. Hahn, D. H., Faubion, J. M. and Rooney, L. W. (1983). Sorghum phenolic acids, their high performance liquid chromatographic separation and their relation to fungal resistance. Cereal Chemistry 60: 255-259.

18. Herrmann, K. (1989). Occurrence and content of hydroxycinnamic and hydroxybenzoic acid compounds in foods. Critical Reviews Food Science Nutrition 28: 315-347.

19. Ihantola-Vormisto, A., Summanen, J., Kankaanranta, H., Vuorela, H., Asmawi, Z. M. and Moilanen, E. (1997). Anti-inflammatory activity of extracts from leaves of Phylllanthus emblica. Planta Medica 63: 518-524.

20. Karnka, R., Rayanakorn, M., Watanesk, S. and Vannesorn, Y. (2002). Optimization of High-Performance Liquid Chromatographic Parameters for the Determination of Capsaicinoid Compounds Using the Simplex Method. Analytical Science 18(6): 661-665.

21. Kaur, S., Grover, I. S. and Kumar S. (1997). Antimutagenic potential of ellagic acid isolated from Terminalia arjuna. Indian J.Experimental Biol. 35: 478-482.

22. Klein, E. S. and Rivera, S. L. (2000). A review of criteria functions and response surface methodology for the optimization of analytical scale HPLC separation. J. Liquid Chromatography Related Technology 23(14): 2097-2121.

23. Loarca-Pina, G., Kuzmicky, P. A., De Mejia, E. G. and Kadoa, N. Y. (1998). Inhibitory effects of ellagic acid on the direct-acting mutagenicity of aflatoxin B1 in the Salmonella microsuspension assay. Mutation Res. 398: 183-187.

24. Meda, A., Lamien, C. E., Romito, M., Millogo, J. and Nacoulma O. G. (2005). Determination of the total phenolic, flavonoid and proline contents in Burkina Fasan honey, as well as their radical scavenging activity. Food Chemistry 91: 571-577.

25. Middleton, E., Kandaswami, C. and Theoharides, T. C. (2000). The effect of plant flavonoids on mammalian cells: Implications for inflammation, heart disease and cancer. Pharmacology Review 52: 673-751. 


\section{Afr. J. Trad. CAM (2006) 3 (1): 115 - 128}

26. Nacoulma, O. G. (1996). Plantes médicinales et pratiques médicales traditionnelles au Burkina-Faso : cas du plateau central ; thèse d'état Université de Ouagadougou, Burkina-Faso, Tome I, 320 pp, Tome II, 261 pp.

27. Nelder, J. A., and Mead, R. (1965). A simplex method for function minimization. Computer Journal 7: 308-313.

28. Onjia, A., Vasilevic, T., Cokesa, D. and Lausevic, M. (2002). Factorial design in isocratic high performance liquid chromatography of phenolic compounds. J. Serbian Chem. Soc. 67(1): 745-751.

29. Op de Beck, P., Cartier, G., David, B., Dijoux-Franca, M. G. and Mariotte, A. M. (2003). Antioxydant flavonoids and phenolic acids from leaves of Lea guineese G. Don.(Leeaceae). Phytotherapy Research 17: 345-347.

30. Privadarsin, K. I., Khopde, S. M., Kumar, S. S. and Mohan H. (2002). Free radical studies of ellagic acid, a natural phenolic antioxidant. J. Agric. Food Chem. 50(7): 2200-2206.

31. Rukkumani, R., Aruna, K., Suresh, V. P. and Padmanabhan, M. V. (2004). Hepatoprotective role of ferulic acid: a dose dependant study. J. Medicinal Food 7(4): 456-461.

32. Schmidtlein, H. and Herrmann, K. (1975). Quantitative analysis for phenolic acids by thin-layer chromatography. J. Chromatography 115: 123-128.

33. Schulz, J. and Herrmann, K. (1980). Analysis of hydroxybenxoic and hydroxycinnamic acids in plant material. II. Determination by gas-liquid chromatography. J. Chromatography 195: 95-104.

34. Thomas-Barberan, F. A., Martos, I., Ferreres, F., Radovic, B. S. and Anklam E. (2001). HPLC flavonoid profiles as markers for the botanical origin of european unifloral honeys. J. Sci. Food Agric. 81: 485-496.

35. Weston, R. J., Mitchell, K. R. and Allen, K. L. (1999). Antibacterial phenolic components of New Zealand honey. Food chemistry 64: 295-301.

36. Wood, A. W., Huang, M. T., Chang, R. L., Newmark, H. L., Lehr, R. E., Yagi, H., Sayer, J. M., Jerina, D. M. and Conney A. H. (1982). Inhibition of mutagenecity of bay-region diolepoxides of polycyclic aromatic hydrocarbons by naturally occurring plant phenols: exceptional activity of ellagic acid. Proceedings of the National Academy of Sciences of the United States of America 79: 5513-5517.

37. Wu, H., Haig, T., Pratley, J., Lemerle, D. and An M. (1999). Simultaneous determination of phenolic acids and 2,4-dihydroxy-7-methoxy-1,4-benzoxazin-3-one in wheat (Triticum aestiVum L.) by gas chromatography-tandem mass spectrometry. J. Chromatography A 864: 315-321.

38. Yin, Y. and Carter, C. W. Jr. (1996). Incomplete factorial and response surface methods in experimental design: yield optimization of tRNA from in vitro T7 RNA Polymerase transcription. Nucleic Acids Research 24(7): 1279-1286. 